\title{
POR UMA HISTÓRIA DA SAÚDE DO VALE DO JEQUITINHONHA: REFLEXÕES SOBRE PRÁTICAS POPULARES DE CURA*
}

Keila Auxiliadora Carvalho ${ }^{1}$

Ramon Feliphe Souza ${ }^{2}$

\begin{abstract}
Resumo: O artigo reflete sobre as práticas populares de cura no Vale do Jequitinhonha, em Minas Gerais, especificamente em duas cidades da região. Para tanto, realizamos uma digressão por períodos específicos do século XIX e início do século XX, a fim de acompanhar como os agentes de cura populares foram alvo dos discursos da medicina científica no Brasil, no momento em que essa última pretendia afirmar sua hegemonia no campo do cuidado com a saúde. Em seguida, observamos os reflexos desse contexto em Diamantina, onde curadores populares foram envolvidos em processos criminais que pretendiam desqualificar as suas práticas. Por fim, no último tópico, com o auxílio da metodologia de História Oral, discutimos a permanência das práticas populares de cura na região, especialmente, benzeções e o uso de plantas medicinais. Argumentamos que, apesar do processo histórico de repressão aos "curadores" não médicos, as práticas populares de cura seguem presentes na sociedade e constituem elemento fundamental da identidade regional.
\end{abstract}

Palavras-chave: Vale do Jequitinhonha; Curas; Populares; Saúde; Região

\section{PARA UNA HISTORIA DE LA SALUD EN EL VALE DO JEQUITINHONHA: REFLEXIONES SOBRE LAS PRÁCTICAS CURATIVAS POPULARES}

Resumen: El artículo reflexiona sobre las prácticas curativas populares en el Vale Jequitinhonha, en Minas Gerais, específicamente en dos ciudades de la región. Para ello, realizamos un recorrido por períodos específicos del siglo XIX y principios del XX, con el fin de seguir cómo los agentes curativos populares fueron el blanco de los discursos de la medicina científica en Brasil, cuando este último pretendía afirmar su hegemonía en el campo del cuidado con la salud. Luego, observamos los reflejos de este contexto en Diamantina, donde

\footnotetext{
* Artigo produzido com os resultados de pesquisa desenvolvida entre 2013 e 2015, no âmbito do Programa de Iniciação Científica e Tecnológica - CICT da Universidade Federal dos Vales do Jequitinhonha e Mucuri UFVJM, sob o projeto "Práticas Populares de Cura: memória, tradição e identidade social no Vale do Jequitinhonha".

${ }^{1}$ Professora Adjunta de História do Brasil Republicano e do Programa de Pós-Graduação em Educação da Universidade Federal dos Vales do Jequitinhonha e Mucuri - UFVJM. Doutora em História pela Universidade Federal Fluminense - UFF. E-mail: keilaacarvalho@gmail.com. https://orcid.org/0000-0001-7607-4557

${ }^{2}$ Mestre em História pelo Programa de Pós-graduação em História das Ciências e da Saúde da Casa de Oswaldo Cruz/Fiocruz. Doutorando em História pela mesma instituição. Graduado em Humanidades e História pela Universidade Federal dos Vales do Jequitinhonha e Mucuri - UFVJM. E-mail: ramon.feliphe@live.com. https://orcid.org/0000-0001-7566-6323.
} 
curadores populares se vieron involucrados en procesos penales que pretendían descalificar sus prácticas. Finalmente, en el último tema, con la ayuda de la metodología de Historia Oral, discutimos la permanencia de las prácticas curativas populares en la región, especialmente las bendiciones y el uso de plantas medicinales. Argumentamos que, a pesar del proceso histórico de represión de los "curadores", las prácticas curativas populares siguen presentes en la sociedad y constituyen un elemento fundamental de la identidad regional.

Palabras clave: Vale de Jequitinhonha; Cura; Popular; Salud; Región

\title{
FOR A HISTORY OF HEALTH IN THE VALE DO JEQUITINHONHA: REFLECTIONS ON POPULAR HEALING PRACTICES
}

\begin{abstract}
The article reflects on popular healing practices in the Jequitinhonha Valley, in Minas Gerais, specifically in two cities in the region. To this end, we toured specific periods of the 19th and early 20th centuries, in order to follow how popular healing agents were the target of scientific medicine discourses in Brazil, at the time when the latter intended to assert its hegemony in the field health care. Then, we observed the reflections of this context in Diamantina, where popular curators were involved in criminal proceedings that intended to disqualify their practices. Finally, in the last topic, with the aid of the Oral History methodology, we discussed the permanence of popular healing practices in the region, especially benzedura (traditional healing) and the use of medicinal plants. We argue that, despite the historical process of repression of non-medical "curators", popular healing practices are still present in society and constitute a fundamental element of regional identity.
\end{abstract}

Keywords: Jequitinhonha Valley; Cures; Popular; Health; Region.

\section{Introdução}

Os rituais - ou, ao menos, as práticas repertoriadas sob essa rubrica - nunca param de recompor sua encenação: eles trazem para dentro dela imagens, gestos e discursos característicos de situações e de épocas diferentes, mas que respondem às novas condições do momento (REVEL, 1998, p. 46).

A reflexão do historiador Jacques Revel traduz, em linhas gerais, aquilo que é nosso esforço nesse artigo: refletir sobre práticas de cura que, em sua maioria, se expressam de forma ritualística. Os conhecimentos implícitos em tais práticas apresentam observações de longa duração e um entendimento próprio sobre saúde e doença, bem como das interações humanas com o meio biofísico da região. Além disso são constitutivos de elementos que compõe a identidade regional do Vale do Jequitinhonha. Diante disso, por meio de discussões fundamentadas no campo da História da Saúde e das Doenças, a ideia é mostrar como as práticas de cura não apenas seguem existindo, como também, em sua "encenação", respondem a questões de seu tempo. Com isso, torna-se possível diversificar as formas de interpretar a história regional - cujo período minerador é o mais destacado -, já que por meio do campo da saúde somos informados sobre as formas de organização social da população e as interações humanas, com o meio ambiente e com a produção e socialização de conhecimentos. 
O Vale do Jequitinhonha é uma região que ocupa 14,5\% do território mineiro com, aproximadamente, $85.000 \mathrm{Km}^{2}$ de extensão territorial, abrangendo 80 municípios. É divido em três microrregiões: Alto Jequitinhonha (região de Diamantina, próxima à nascente do rio); Médio Jequitinhonha (região de Araçuaí) e Baixo Jequitinhonha (região de Almenara, próximo à foz, no sul da Bahia) (Nascimento, 2009). A região está circunscrita à Serra do Espinhaço que, conforme destacado por Saadi (1995), se constitui como um "conjunto de terras altas" no sentido norte-sul entre os estados de Minas Gerais e Bahia com cerca de $1.200 \mathrm{Km}^{2}$ de extensão (Saadi, 1995, p. 41). Reconhecida em 2005 pela Unesco, como Reserva da Biosfera, a Serra do Espinhaço abrange as bacias hidrográficas de importantes rios brasileiros como: São Francisco, Jequitinhonha e Doce; além disso, destacam-se o encontro dos biomas nacionais: Cerrado, Mata Atlântica e Caatiga, bem como espécies de fauna e flora endêmicas. Destacar as suas características ambientais é fundamental, pois são chaves importantes para compreender a colonização regional, ocorrida em finais do século XVII, a partir da exploração de diversos recursos naturais - como madeira e drogas do sertão - e, posteriormente, minérios - em particular, mineração de ouro e diamantes.

A diversidade regional também se revela nas manifestações culturais, que apresentam traços da cultura indígena e negra (Nascimento, 2009). Entretanto, como destacou Servilha (2015), apesar da profunda heterogeneidade regional, abundam representações que interpretam o Vale e sua população apenas sob a perspectiva da pobreza. Esse autor analisou como atraso e miséria tornaram-se marcas de um Vale do Jequitinhonha delimitado política e administrativamente com fins de planejamento e de interesses nem sempre públicos (Servilha, 2015, p.83). Dito isso, o presente artigo ultrapassa a ideia de "vale da miséria", ao considerar as variadas perspectivas para interpretar e, por conseguinte, "re-significar" essa região. Pois, como destacou Gerrero (2009), além dos aspectos materiais, "a dimensão simbólica da pobreza, está sujeita à normas, costumes, valores, necessidades que variam e se transformam, histórica e geograficamente" (Gerrero, 2009, p.91). Tal como argumentou Ribeiro (2008), o "Vale do Jequitinhonha" são muitos, tanto quanto são os diferentes olhares e representações que distintos atores sociais produzem ao seu respeito.

$\mathrm{O}$ artigo está dividido em três tópicos. No primeiro, apresentamos o resultado da pesquisa bibliográfica em torno da questão do confronto entre o saber médico oficial e práticos populares de cura, entre o final do século XIX e início do século XX. No tópico seguinte, verificamos a partir do município de Diamantina os reflexos dessa conjuntura na região do Norte de Minas Gerais - nomenclatura que atualmente corresponde a região do Alto Vale do 
Jequitinhonha. No terceiro e último tópico, discutimos a continuidade das práticas populares de cura na região.

\section{As artes de curar no Brasil}

Dom divino, feitiçaria, saberes transmitidos oralmente de geração em geração, são exemplos da gama de explicações para práticas populares de cura que guardam aspectos importantes das culturas branca, indígena e negra que se misturavam durante o período da colonização regional, iniciado em finais do século XVII. Ministradas com o objetivo de cura ou prevenção de certos males, as práticas eram diversas: benzeções, rezas, garrafadas, banhos externos entre outros. Tais práticas se consolidaram em diversas regiões brasileiras concorrendo com outras artes de curar, sobretudo, com o saber médico-científico.

De acordo com Ribeiro (2014), a descoberta da América contribuiu para a ampliação do conhecimento herbário e sua utilização no Velho Mundo, especialmente divulgado por aventureiros, viajantes, naturalistas e boticários. É importante enfatizar que além da flora medicinal, aspectos místicos relacionados às artes de curar também foram considerados e incorporados pelos distintos saberes que se encontraram no Novo Mundo.

Souza (1986), observou que os "traços católicos, negros, indígenas e judaicos misturavam-se, pois, na colônia, tecendo uma religião sincrética e especificamente colonial" (Souza, 1986, p.97). Por isso, a multiplicidade de tradições religiosas ou pagãs não eram apenas traços remanescentes daquela sociedade, mas, antes, "inseria-se, neste sentido, no cotidiano das populações. Era, portanto, vivência" (Souza, 1986, p.98). Desse emaranhado complexo de tradições e vivências é que resultaram muitas práticas e representações acerca dos fenômenos de saúde e doença no Brasil.

Com a vinda da família real para o Brasil em 1808, e a mudança de status de colônia para sede do Império português, ocorreram significativas transformações nos âmbitos políticos, econômicos e, sobretudo culturais (Almeida, 2010). Em 1808, por exemplo, foi criado um órgão com sede na cidade do Rio de Janeiro que se constituiu como o principal responsável pela regulação e fiscalização do exercício das artes de curar no Brasil, a Fisicatura-mor (Pimenta, 2003). Tal órgão atuou emitindo licenças e cartas de autorização para quem quisesse exercer alguma atividade relacionada às artes de curar até sua extinção, em 1828. Segundo Pimenta (2003), este tipo de regulamentação já existia em Portugal pelo menos desde o século XIII.

No Brasil, as autorizações foram diversas e entre elas podemos destacar: médico, cirurgião, boticário, sangrador, parteira e curandeiro; também eram emitidas licenças a 
praticantes de "medicina prática" - geralmente concedidas à cirurgiões que queriam receitar remédios para moléstias internas -; e a dentistas, atividade amiúde associada à de sangrador (Pimenta, 2003, p.308). As cartas de autorização foram distribuídas de acordo com as diferenças sociais e econômicas entre os agentes praticantes. Diante disso, observamos que os curandeiros, os sangradores, as parteiras, entre outros, compuseram a categoria de "terapeutas populares", tendo sido menos valorizados do ponto de vista da Fisicatura-mor. Nessa lógica, a concessão dos títulos afirmava o "maior ou menor prestígio que as pessoas recebiam" (Pimenta, 2003, p. 308). Ou seja, as cartas e licenças emitidas, demonstravam que existia oficialmente uma hierarquia entre os curandeiros da época.

De acordo com Almeida (2010), o suplicante para atuar legalmente no "ofício de curandeiro" recebia uma licença provisória, de um (01) ano, assinada pelo físico-mor ou o delegado. Sangradores e parteiras também precisavam renovar anualmente suas licenças e no caso delas, porém, a assinatura deveria ser do cirurgião-mor. Por outro lado, médicos, cirurgiões e boticários, recebiam cartas definitivas para atuarem em suas artes, e estas eram assinadas pelo rei, príncipe ou imperador. Portanto, essas assinaturas os distinguiam socialmente (Almeida, 2010, p.14).

Qualquer pessoa poderia se dirigir a Fisicatura para obter a carta ou licença provisória. Para isso, segundo Tânia Pimenta (2003), bastaria que fosse apresentado um atestado assinado pelo mestre com que havia aprendido a arte de curar. A autora acrescenta que, "com alguma frequência, esse atestado era substituído por uma declaração de pessoas importantes da comunidade onde atuava o terapeuta", ou ainda, poderia obter a autorização por meio de “abaixo-assinados da própria comunidade” (Pimenta, 2003, p. 309).

Existia uma série de punições, bem como multas e até mesmo prisões para terapeutas não oficiais que fossem flagrados praticando curas. Porém, a Fisicatura, na prática, “estava em desvantagem na tentativa de cumprir suas funções" (Pimenta, 2003, p. 310). Tendo em vista que não havia delegados e subdelegados do órgão para atuar, em número suficiente, no vasto território do país a ser fiscalizado. Ademais, estudos mostram que os pedidos de licenciamento representavam apenas $1 \%$ do total das especialidades de cura que eram aceitáveis pela Fisicatura-mor (Almeida, 2010, p. 15). Pimenta (2003), afirma que a oficialização das atividades não despertou grande interesse aos práticos populares - curandeiros, parteiras, sangradores entre outros. A autora chegou a essas considerações a partir da análise do número de licenças e cartas concedidas às referidas categorias. Durante os 20 anos de atuação da Fisicatura no Rio de Janeiro, apenas 207 sangradores, 66 parteiras e 27 curandeiros se oficializaram no Brasil, o que corresponde respectivamente a $16 \%, 5 \%$ e $2 \%$ do total de títulos 
expedidos. Situação que destoa radicalmente do constatado em outras fontes que fazem referência a presença desses terapeutas disseminadas pelo Brasil (Pimenta, 2003, p. 310).

E, como destacado por Almeida (2010), os números apresentados pela Fisicatura-mor não representam a realidade do cotidiano daqueles que adoeciam nas primeiras décadas do século XIX, e que se serviam largamente dos serviços dos curadores. Não obstante, para a mesma autora, não há indícios de que a população preferisse um curador licenciado. Assim, a licença tornava o profissional mais bem-conceituado apenas diante da Fisicatura-mor, e a maioria dos curadores atuavam nos cuidados à população sem requer a licenciatura para fazêlo. Os médicos, por outro lado, não podiam simplesmente denunciar tais práticas como "charlatanismo" ou "ignorância popular", já que isso implicaria em confronto direto com os hábitos de grande parte da população. De modo que, segundo Ferreira (2003), se viam obrigados a dialogar com a tradição médica popular.

As considerações feitas até aqui evidenciam que, no século XIX, a medicina acadêmica não havia sido totalmente "desvinculada dos elementos mágicos e religiosos a que esteve associada até fins do século anterior" (Almeida, 2010, p. 27). Contudo, a partir da década de 1830, é possível observar um maior empenho político dos médicos diplomados na disputa pelo monopólio na arte de curar, levando a um afastamento dos elementos mágicos e religiosos. Com isso, aumentou-se o apelo para a criação de uma legislação que assegurasse o controle das práticas de curar pelos acadêmicos, ou seja, o monopólio desse ofício. Essa premissa foi constante nos discursos médicos, que passaram a desqualificar as práticas de cura populares, sobretudo, a partir da veiculação de periódicos (Almeida, 2010).

As estratégias para criar uma hegemonia da medicina acadêmica sobre as artes de curar se deram de variadas formas, com destaque para: investida contra o charlatanismo, críticas à criação desordenada de novos cursos de medicina, sindicalização, normatização e organização do trabalho médico, utilização do argumento científico (Carvalho, 2008, p. 60). Notadamente, podemos mencionar a criação das faculdades de medicina do Rio de janeiro e da Bahia em 1832 e, especialmente, a grande expressão alcançada pelo movimento sanitarista, já no século XX, como importantes indicadores do distanciamento cultural entre a medicina culta e outros saberes.

No bojo destas transformações, a categoria médica procurou chamar a atenção das autoridades para o problema que significaria o exercício ilegal da medicina, ao mesmo tempo em que buscavam a institucionalização de sua profissão. Com efeito, o médico chegou ao século XX lutando para se posicionar na arena política e social. 
A ciência médica assumiu a partir da primeira década da República (1889) uma função preventiva e social, em detrimento do papel predominantemente curativo que antes desempenhava (Schwartzman, 1979). Para tanto, os médicos sanitaristas criaram uma retórica procurando legitimar a imagem da medicina como uma ciência capaz de contribuir com o processo de superação do atraso da nação. Neste contexto, as artes de curar não procedentes do campo científico passaram a ser combatidas, sendo associadas a: superstições, magia, ignorância e atraso. A imposição do saber médico, portanto, implicaria em um movimento de descrédito em relação às tradições referentes à arte de curar, a qual muitas vezes era "regida por outra lógica, que percorria o espaço da fé, da crença, da solidariedade e da tradição" (FIGUEIREDO, 2002, p. 47).

E, além do argumento de caráter científico, a Igreja Católica também mobilizou discursos de repressão aos curadores populares. Em Minas Gerais, especificamente, a Igreja Católica teve atuação determinante nos rumos assumido pelo processo de repressão às práticas populares de cura. Vieira (2015), em estudo sobre as práticas curativas exercidas por um sacerdote que viveu na cidade mineira de Mariana, no período de 1859 a 1933, demonstrou como os discursos acerca da saúde e da doença foram estratégias importantes do projeto de reforma do clero e da sociedade. O autor argumenta que a forma como Igreja Católica dava sentido às doenças também revelavam um combate contra tudo aquilo que a instituição denominou de "moralidade duvidosa" (Vieira, 2015, p. 6). A busca por essa primazia divina na cura colocou em justaposição as terapias populares.

A perseguição aos curadores populares, portanto, mobilizou diversos atores sejam amparados tanto pela religião quanto pela ciência. Sobretudo essa última, esteve profundamente atrelada às estratégias utilizadas no processo de consolidação da hegemonia médico-acadêmica no campo da saúde. A difusão desse discurso de combate às práticas populares de cura teve na imprensa um grande aliado. Diversos periódicos apresentavam recomendações baseadas no que era considerado, na época, como preceitos modernos da higiene, ao mesmo tempo em que denunciavam os praticantes de artes de cura não reconhecidos como oficiais. A seguir, analisamos reflexos desse contexto no município de Diamantina, no início do século XX, com foco na perseguição aos agentes populares de cura. Na tradicional imprensa diamantinense ${ }^{3}$, como observou Goodwin Júnior (2007), as elites letradas encontraram uma espécie de tribuna,

\footnotetext{
${ }^{3}$ Desde 1828 circulavam publicações seriadas locais, o arraial do Tejuco, antiga denominação de Diamantina, se constituiu como a terceira região de Minas Gerais a instalar a imprensa (A Idea Nova, 04/04/1909, p. 1). Ao longo do século XIX, mais de 70 títulos diferentes circularam na localidade. Os diversos periódicos floresceram como resultados do intenso debate político entre as elites regionais (GOODWIN Jr., 2007, p. 49).
} 
na qual puderam eleger e destacar alguns elementos como "sinais visíveis de civilização". Assim, várias questões foram levantadas nas páginas dos jornais locais como: o espaço urbano - seus edifícios públicos, a água, o esgoto, as moradias, os animais -, e os hábitos dos citadinos. A perspectiva era a superação de hábitos e valores percebidos como incivilizados ou arcaicos, essa dimensão incluiu as práticas de cura não oficiais, como veremos adiante.

\section{Perseguição a agentes populares de Cura em Diamantina}

Viscardi (2012), observa que, nos primeiros anos da República, uma das características da imprensa mineira era a produção de uma forte propaganda de "denúncias, que apontavam para o caos vivido pelo país e para a inoperância dos dirigentes na solução dos problemas mais prementes" (Viscardi, 2012, p. 154). Essa tendência também foi verificada em periódicos diamantinenses. Para fins deste artigo, destacamos algumas manchetes que circularam no jornal A Idéa Nova, que empreendeu um forte movimento em favor de uma reestruturação da urbe da cidade. Manchetes, cujos títulos eram "Águas e Esgotos", O Sarampo", "Cura da Varíola", "Pelo Extremo Norte", "Contra as Formigas"4, recorrentemente chamavam atenção para a falta de estrutura da região, bem como destacavam aspectos relativos aos hábitos higiene (ou ausência de hábitos de higiene considerados modernos) - da população.

O paradigma da bacteriologia que, gradativamente se tornava mais frequente nos discursos dos jornais diamantinenses ${ }^{5}$, contribuiu para demonstrar que outros fatores poderiam ser responsáveis pelo processo de transmissão da doença. Assim, aspectos do cotidiano: os cuidados no preparo dos alimentos e no contato com o outro, por exemplo, cada vez mais passaram a ser associados como elementos que influenciam na proliferação de doenças.

Em outro jornal, O Municipio, observamos algumas dicas de higiene, sob forma de crítica acerca de um hábito comum à época: “escarrar-se em assoalho". Tal hábito, na perspectiva apresentada pelo jornal, além de incivilizado, consistia em um dos principais propagadores da tuberculose, denotando falta de asseio e danos à saúde pública. Na edição de

\footnotetext{
${ }^{4}$ As matérias cujos títulos foram citados estão respectivamente em: A Idéa Nova, 08/10/1911, p.1; 18/07/1909, p.2; A Idéa Nova 18/12/1910, p. 1; A Idéa Nova, 08/10/1911, p. 1 \& A Idéa Nova, 18/12/1910, p.3.

${ }_{5}^{5}$ No final do século XIX, estudos como o de Louis Pasteur e Robert Koch contribuíram para o avanço da microbiologia como ciência. Muitos debates foram, inclusive, vulgarizados na imprensa. Os estudos de Pasteur forneceram evidências de que os microrganismos não eram frutos de um "aparecimento espontâneo". O processo denominado fermentação, desenvolvido por Pasteur, contribuiu de forma fundamental para a relação entre microrganismos e doenças. Robert Koch, por sua vez, se constituiu como um dos primeiros cientistas a apresentar evidências de que as bactérias causavam doenças. No ano de 1876. em seus estudos cultivou uma bactéria em forma de bastão (Bacillus anthracis) e injetou amostras da cultura em animais sadios. Koch isolou a bactéria do sangue dos animais e, a partir disso, relacionou o micróbio específico a uma doença específica, a tuberculose (Tortora et al, 2000, p: 08).
} 
10 de novembro de 1900, recomendava-se aos leitores que evitassem o consumo de bebidas alcoólicas, uma vez que o álcool era "porta de entrada para o mal maior", a tuberculose. Foi possível observar na análise do periódico que havia uma forte argumentação, procurando condicionar os ideais de modernização aos hábitos dos moradores locais. Como destacado na matéria "a vigilância mais severa seja a arma de cada um, e que nos alimentos, no ar, na água, nos objetos que tocamos. Se tema o inimigo, se veja o germe do mal, se precinta o micróbio da tuberculose" (O Municipio, 10/11/1900, p.3.)

Assim, diante das mudanças na compreensão dos processos relacionados à doença e à saúde, as práticas não oficiais passaram a sofrer duras críticas da imprensa. A autoridade médica foi ampliada a ponto de ir além da doença, também ser exercida sobre a saúde e, nesse contexto, o principal alvo da repressão era o curandeiro não médico. Contudo, malgrado a esse processo que teve protagonizado por diversos atores, destacadamente intelectuais e médicos, a população continuou se valendo de mandingas, rezas, orações e, em alguns casos, ervas medicinais entre outros meios, a fim de alcançar o bem-estar físico ou espiritual. Como indica o estudo de Figueiredo (2002) sobre as artes de curar em Minas Gerais, os praticantes dessas artes atendiam pessoas de diversos segmentos sociais, uma vez que o hábito de se recorrer aos curandeiros não era (e continua não sendo) uma prática feita somente por aqueles que não possuíam recursos para ir a médicos.

No jornal O Municipio, edição de 28 de abril de 1901, um homem qualificado como charlatão foi interrogado pelo delegado de Higiene da cidade de Diamantina, Alexandre da Silva Maia. O suposto charlatão, cujo nome era Aprígio, foi identificado no jornal como o curandeiro Lages. O jornal afirmava que por falta de espaço e por não haver "nada de curioso ou do interesse dos leitores no interrogatório de Aprígio, "não voltariam a se preocupar com o ocorrido" (O Municipio, 18/05/1901, p.3). No entanto, embora asseverassem o encerramento do caso, verificamos, em pelo menos duas edições seguintes, menção a ele. A dificuldade na definição acerca da relevância do interrogatório do curandeiro, faz-nos inferir que poderia haver a quem interessasse o desenrolar do processo. Talvez os médicos e outros agentes da incipiente rede de saúde da cidade de Diamantina no período, pretendessem popularizar o caso, para dar visibilidade aquilo que identificaram à época como os perigos do charlatanismo.

Voltando ao caso do curandeiro de Lages, a edição de 18 de maio de 1901, do mesmo periódico trouxera a seguinte narrativa:

Embora prometêssemos em o nosso número passado, deixamos de publicar o interrogatório a que foi submetido o Aprígio, por que nele nada encontramos de curioso o que interesse aos nossos leitores. O curandeiro, sendo interrogado pelo dr. Delegado de higiene, respondeu que somente aplica como remédio 
algumas plantas medicinais, como abóbora do mato, pireto, carobinha, etc. Quanto as adivinhações, é habilidade muita que o finório tem para chuchar os dez mil reis do pobre ingênuo que o procura para consultar $(\mathrm{O}$ Municipio 18/05/1901, p.4).

A retórica da notícia associava a procura do curandeiro aos comportamentos de “ingenuidade e ignorância" da população, por não ter consciência dos males que o charlatão poderia causar à sua saúde, bem como de estar sujeita à exploração financeira. Segundo Nogueira (2013), há estudos que indicam que os povos oriundos da Europa e África acreditavam que pessoas poderiam manipular forças sobrenaturais para provocar o mal. $\mathrm{O}$ autor afirma que, nos núcleos coloniais das Minas Gerais setecentistas, indivíduos de "diversas procedências, estratos sociais, condições jurídicas e culturas" comungavam o medo do feitiço (Nogueira, 2013, p. 47). O caso de Aprígio, já no século XX, indica que essas explicações, de ordem sobrenatural, ainda eram compartilhadas pelos indivíduos da sociedade diamantinense. Como notado, o curandeiro Aprígio fazia uso de plantas, mas também de adivinhações - um gesto mágico - importante para a eficácia da cura, já que o curador, como bem definiu Almeida (2010), precisaria “"olhar a doença', ver o mal que existe e se é algum mal feito que ele precisava cortar" (Almeida, 2010, p.36).

Combater o charlatanismo era uma questão política que, na perspectiva médica, contribuiria para o progresso da nação, pois permitiria uma visão mais racional sobre a saúde. A batalha discursiva contra as práticas dos charlatões torna-se cada vez mais evidente quando acompanhamos último relato sobre Aprígio, publicado na edição de 30 de setembro de 1901, a qual afirmou que trataria das "supostas curas do astucioso Aprígio, de que os nossos leitores estariam lembrados" (O Municipio 30/09/1901, p.4). E seguia a notícia destacando que delegado municipal, no cumprimento de seu dever, havia feito o suposto charlatão ir à cidade e o intimou a não continuar com o seu pernicioso meio de vida. Mas que, não obstante às ordens do delegado,

o famigerado espertalhão transferiu a sua residência para a sede do distrito de Mercês de Arassuahy, onde, certamente estabelecerá o seu consultório, cabe ao subdelegado de polícia daquela localidade proibir que tão audaz milagreiro aplique seus remédios por serem muito perigosos (O Municipio 30/09/1901, p.4).

Aprígio fora definido pela imprensa como "espertalhão e milagreiro" e suas práticas foram definidas como "astuciosas e muito perigosas". O vocabulário ofensivo demonstrava o processo de construção de uma hegemonia da categoria médica sobre as práticas de cura. Censurado por exercer suas práticas em Diamantina, se deslocou para o distrito de Mercês de 
Arassahy, atual cidade de Senador Modestino Gonçalves. Não sabemos se lá o curandeiro continuou exercendo a prática de curar.

O caso acima nos dá indícios de como a desqualificação dos curadores foi um processo lento e marcado por continuidades e rupturas. Como afirmou Almeida (2010), os processos sofridos por agentes de curar não médicos, bem como a caracterização negativa de suas práticas, não implicaram na aceitação passiva e imediata da sociedade à medicina acadêmica (Almeida, 2010, p.66). Os variados discursos contra os "charlatães" não obtiveram progressos imediatos, no sentido de inserir a medicina acadêmica entre os costumes usuais da população brasileira, ao contrário, mostrou-se como um processo lento e marcado por continuidades e rupturas. Como bem observou Figueiredo (2002), a tradição é tão persistente quanto à "pressão das inovações e novidades" (Figueiredo, 2002, p. 77).

Mais do que uma disputa ou uma concepção do discurso médico oficial como triunfante, observamos também estratégias que ora aproximavam e ora distanciavam o saber oficial e as artes de curar. No artigo intitulado "O Elixir da Vida" (Carvalho \& Souza, 2016), analisamos anúncios do medicamento intitulado Elixir M. Morato, amplamente divulgado em jornais que circulavam em Diamantina, no século XIX. Argumentamos que, embora os médicos denunciassem aqueles que praticavam a cura na informalidade, o faziam a partir de uma linguagem muito próxima dos curadores populares, valendo-se de seus argumentos e, muitas vezes, perpassando o universo das crenças populares. Assim, expressões como: santo remédio, milagre, erva indígena, entre outras, eram largamente utilizadas pelos doutos na arte de curar.

Podemos afirmar que, no início do século $\mathrm{XX}$, as disputas em torno da hegemonia sobre o conhecimento e exercício das práticas de saúde continuavam na ordem do dia. Asseveramos isso, a partir de indícios como do curandeiro Aprígio e tantos outros que encontramos e, a seguir, citamos mais um caso. Na edição de 15 de dezembro de 1907, do jornal A Idéa Nova foi noticiado na primeira página que o "africano e feiticeiro", Alexandre Cuanga, parecia ter "larga clientela entre grande parte do povo supersticioso, pois já tem sido preso várias vezes por charlatanice". A procedência de Alexandre foi destacada como forma de desqualificá-lo frente à sociedade. Diferente do caso de Aprígio acusado de adivinhações, Cuanga fora caracterizado como feiticeiro, cuja atuação colocava em risco a vida daqueles que lhe procurava. É importante destacar que das informações que temos do curandeiro de Lages nada costa sobre sua cor ou procedência, ao passo que Cuanga é identificado como homem negro e, portanto, perigoso, conforme pode ser observado na narrativa do jornal:

Uma mulher, moradora na rua do Amparo, convenceu-se que estava enfeitiçada e que tinha uma lagartixa no cérebro, no lugar em que outras 
mulheres tem os miolos (...). Enfim a infeliz enlargatixada chamou o Cuanga, pagou-lhe naturalmente e dele recebeu uma garrafa de cachaça, preparada com umas raízes (...). Mal provou o cálice, caiu, quase veio desta para melhor. $\mathrm{O}$ dr. Antônio Mota, chamado a tempo, receitou-lhe um calmante e levou o remédio do feiticeiro para analisá-lo (A Idéa Nova, 15/12/1907, p. 1).

É muito clara a distinção entre aquele que pode matar - o curandeiro, suposto feiticeiro - e aquele que pode salvar - o médico. Os sintomas da mulher descritos no jornal, se aproximam da descrição que Nogueira (2013) faz acerca dos efeitos dos feitiços nas Minas Gerais setecentistas, a saber: feitiço "como coisa feita" se alojava no organismo dos enfeitiçados, entrando de "forma fora do natural" (Nogueira, 2013, p.89). Embora se trate de períodos distintos e, considerando a escassa bibliografia sobre as artes de cura na região no início do século XX, acreditamos que a "anormalidade" na descrição que o jornal faz dos sintomas da mulher, aproximam o ocorrido da definição de feitiço proposta pelo autor. O relato da "enlargatixada" é mais uma evidência de que no processo de repressão a esses agentes na Diamantina do início do século XX, construiu-se uma narrativa que lançava mão de concepções das próprias crenças populares como forma de combatê-las, a ideia de que corpos poderiam ser alvos de feitiços, era uma delas.

\section{Práticas de Cura em cidades do Alto Vale do Jequitinhonha}

Na seção anterior discutimos brevemente aspectos da repressão a agentes de cura não oficiais, que foram alvo de críticas em jornais diamantinenses no início do século XX. Contudo, é importante salientar que essas fontes não são neutras. Como temos evidenciado, elas defendiam interesses bem definidos. A repressão aos agentes citados revela um contexto que ultrapassava o discurso de saúde e doença, colocando em questão, por exemplo, aspectos da religiosidade marcadamente católica da região que, desde 1864 era sede de um bispado católico. Além disso, havia também projetos das elites regionais que buscavam localizar Diamantina nos discursos sobre a modernidade do período, para que fossem combatidos os aspectos reconhecidos como atrasados e, portanto, incompatíveis com os novos preceitos do mundo moderno. Contudo, o processo de "sacralização" do saber médico-científico e a repressão às outras práticas de curar não foram suficientes para extinguir estas últimas.

Dito isso, se esses registros pouco nos informam sobre esse contexto na perspectiva dos agentes populares, acreditamos que a metodologia da história oral, utilizada neste último tópico, oferece subsídios para refletimos sobre as práticas populares de cura ainda realizadas na região. Dando visibilidade às histórias, receitas, memórias e conhecimentos dos indivíduos envolvidos 
na perpetuação de tais práticas. Assim, focalizamos dois municípios do Alto Vale do Jequitinhonha -Diamantina e Couto de Magalhães de Minas (antigo distrito do município de Diamantina) -, a fim de refletir sobre as práticas que se perpetuam na região. Obviamente, essas localidades não representam a totalidade do universo das práticas de cura popular, mas acreditamos que ajudam a entender aspectos das relações estabelecidas com o meio ambiente, das experiências do sagrado e das dinâmicas sociais. Foram entrevistadas nove pessoas, sendo a maioria do sexo feminino, seis mulheres. A escolha dos depoentes, por sua vez, ocorreu devido à "fama” que eles possuíam em suas cidades. As práticas populares mais comuns realizadas entre eles são: benzedura e uso de plantas medicinais que, muitas vezes, são exercidas em conjunto.

Estudos etnobotânicos indicam que é expressiva a utilização de plantas medicinais no Vale do Jequitinhonha, mesmo nas áreas urbanas. Indicam também que esse conhecimento tem se transmitido, em particular, pelas relações familiares - de pais para seus filhos -, em especial, das mães para seus filhos. Além disso, que há, por parte dos práticos, a percepção de que o interesse de gerações mais novas tem se tornado cada vez menor (Costa, 2020 \& Cruz et al, 2015). As informações reunidas a partir das entrevistas realizadas em Diamantina e Couto de Magalhães, caminham na direção desses apontamentos. Tal como afirmou J. V. da Silva, da cidade de Couto de Magalhães de Minas, "as gerações mais novas, não querem aprender (...) e, muitas vezes, tem vergonha". Entretanto, se depender da disposição do depoente, esse saber continuará a se perpetuar, pois afirmou ter prazer em ajudar a preservar "uma coisa que vem desde o começo do mundo".

De modo geral, as grandes referências em se tratando do uso e da perpetuação das práticas populares de cura, são mulheres. Em sua narrativa, o J. V. da Silva disse-nos que, ainda na infância, recebera "o dom divino" que o possibilitava rezar para remediar: peçonhas de animal, picadas de insetos, engasgo e, além desses males físicos, os de outra ordem como "quebrando, um mal olhado ou um vento virado". Sua narrativa acerca de como teria aprendido a benzer nos dá indícios da estreita relação desse saber com uma cultura popular não escrita. Segundo ele, aprendeu a realizar orações com os seus pais. Relata que quando criança, se engasgou com um bocado de farinha: "eu senti que eu ia morrer naquela hora, perdendo o fôlego e levando a mão pro lado da minha mãe". Ao perceber a situação de seu filho, a mãe voltou-se em direção as suas costas e o benzeu. Como ele afirma: "fez a benzição (...) aí bateu três vezes nas minhas costas e eu desengasguei” (J. V. Silva, 2014). E seguiu narrando que, no dia seguinte ao incidente, manifestou o interesse em aprender a oração com sua mãe (J. V. Silva, 2014). 
A narrativa de outra depoente, residente no município de Diamantina, Mãe Lia de Oxum, também destacou o desinteresse das novas gerações. Relatando um caso próximo, a depoente afirmou que uma das suas filhas não tinha interesse em aprender. Disse que um dos seus netos, que residia com ela, havia copiado algumas orações. Com alívio, afirmou: "ele tem três menino também, na hora do aperto ele já vai se livrar (...)”, já em relação a filha, afirmou: “se eu morrer ela não vai saber benzer um menino!". A seguir a narrativa da nossa depoente ensinando como "cortar cobreiro":

Pega a faca e faz a oração: O que que eu corto; cobreiro verde, sapo, sapão, aranha, aranhão, lagarto, lagartão e todos os bichos de (inaudível). Para que não se renda mais eu tiro o rabo, a cabeça e os "lado". E vai fazendo a cruz ali com a faca e "cê" tá cortando! Outros corta com tesoura, qualquer coisa que corta, "né”? Então pra cada coisa tem uma oração (Mãe Lia de Oxum, 2014).

Embora os entrevistados enfatizem que é pequeno o interesse das novas gerações, observamos que a procura por orações ou indicação de plantas para remediar males era constante. Segundo afirmação de J. V. da Silva,: “tem dia que vem seis, oito 'pessoa' pra benzer. Tem dia que vem muita gente pra benzer" (J. V. Silva, 2014). Em sua narrativa, Mãe Lia afirmou também que seria devido à grande procura das pessoas para se curarem de seus males que a arruda em seu quintal não nasce "porque quando começa a brotar vem uma 'renca' de menino pra benzer" (M. A. dos Anjos Silva, 2014).

Além dos saberes que envolvem a dimensão espiritual, os nossos entrevistados possuem amplo conhecimento sobre a flora nativa da Serra do Espinhaço. Nos depoimentos foram relatadas 43 espécies de plantas de usos diversos (cosméticos, preparação de alimentos, limpeza espiritual, diurético). Apenas em uma única entrevista, a de Mae Lia, por exemplo, foram indicadas 23 espécies de plantas que eram utilizavas para fins diversos, desde males do corpo aos do espírito. As indicações mais recorrentes foram as espécies: boldo, sálvia, capim-cidreira, erva-cidreira, alevante, alfavaca, hortelã e a romã. Destacadamente, as partes mais indicadas para uso foram as folhas.

Considerando a importância dos saberes compartilhados por nossos entrevistados, elaboramos a tabela a seguir apresentando algumas das espécies indicadas nas entrevistas. 
TABELA 1: Espécies vegetais de uso múltiplo citadas por moradores de Couto de Magalhães de Minas e Diamantina, MG.

\begin{tabular}{|c|c|c|}
\hline Nome Popular & Nome Científico & Indicação Popular \\
\hline Alecrim & $\begin{array}{l}\text { Rosmarinus officinalis } \\
\text { L. }\end{array}$ & Antimicrobiana \\
\hline Arruda & Ruta graveolens $L$ & $\begin{array}{l}\text { Resfriado, calmantes, } \\
\text { espiritual* }\end{array}$ \\
\hline Artemísia & $\begin{array}{l}\text { Tanacetum parthenium } \\
\text { (L.) Sch. Bip. }\end{array}$ & Dor de cabeça \\
\hline Alevante & Mentha viridis & Gripe \\
\hline Babosa & Aloe Vera (L.) & Cicatrizante \\
\hline Bálsamo & Sedum Dendroideum & Dor do estômago \\
\hline Bardana & $\begin{array}{l}\text { Arctium Minus (Hill) } \\
\text { Bernh }\end{array}$ & Depurativo \\
\hline Boldo & $\begin{array}{l}\text { Plentranthus barbatus } \\
\text { Andrews }\end{array}$ & Dor hepática \\
\hline Café & Coffea arabica $L$ & Espiritual* \\
\hline Canguçu Branco & & Soro-antiofídico (Natural) \\
\hline Cana do Brejo & Costus spicatus swartz & Depurativo \\
\hline Capim Cidreira & & Calmante \\
\hline Capim de São José & & Espiritual* \\
\hline Carapiá & Cordia superba & Gripe \\
\hline Carqueja & $\begin{array}{l}\text { Baccharis trimera } \\
\text { (Less.) }\end{array}$ & Diurética \\
\hline Carobinha & & Depurativo \\
\hline Cervejinha do Campo & Arrabidaea brachypoda & Problemas renais \\
\hline Cipó Formiga & & Hematomas \\
\hline Confrei & Symphytum officinale & Úlceras gástricas \\
\hline Espada de São Jorge & Sansevieria trifasciata & Espiritual* \\
\hline Erva Doce & $\begin{array}{l}\text { Foeniculum vulgare } \\
\text { Mill }\end{array}$ & Expectorante \\
\hline Erva Cidreira & Lippia alba & Pressão Alta \\
\hline Salsaparrilha & Smilax aristolochifolia & Anti-reumática \\
\hline Alfavaca & Ocimum basilicum. & Culinária e Espiritual* \\
\hline Gervão & Verbena officinalis & Antibiótico \\
\hline Giné & Petiveria tetrandra & Analgésica \\
\hline Goiaba & Psidium guajava & Adstringente \\
\hline Hortelã & Mentha $s p$ & Gripe, Verminose \\
\hline Incenso & Commiphora myrrha & Aromática e Espiritual* \\
\hline Jaborandi & Piper jaborandi. & Cosmético \\
\hline Japecanga & Smilax brasiliensis & Diurético \\
\hline $\begin{array}{lll}\text { Lágrima de } & \text { Nossa } \\
\text { Senhora } & & \\
\end{array}$ & Coix lacryma-jobi & Depurativo \\
\hline Mamona & Ricinus communis & Vermífugo e Espiritual* \\
\hline Manjerona & ----- & Calmante \\
\hline Mangaba & Harconia speciosa & Depurativo \\
\hline Pinhão Roxo & Prunus spinosa & Purgante \\
\hline Pitanga & Stenocalix pitanga & Vermífuga \\
\hline Quebra Pedra & Phyllanthus niruri & Depurativo \\
\hline
\end{tabular}




\begin{tabular}{|l|l|l|}
\hline Quina de Vara & $\begin{array}{l}\text { Cinchona calisaya, } \\
\text { Cinchona officinallis }\end{array}$ & Adstringente \\
\hline Romã & Punica granatum L. & Inflamação de Garganta \\
\hline Sálvia & Salvia officinalis L. & Antiespasmódica \\
\hline Saião & $\begin{array}{l}\text { Kalanchoe brasiliensis } \\
\text { Cambess. }\end{array}$ & Antimicrobiana \\
\hline Tanchagem & Plantago major & Diurética \\
\hline Velame Branco & Macrosiphonia Martii & Depurativo \\
\hline
\end{tabular}

*Ligado às relações mágicas como, por exemplo: abertura de caminhos, banhos de descarrego etc.

Fontes: Informações coletadas em pesquisas de campo a partir das entrevistas realizadas com depoentes do município de Diamantina e Couto de Magalhães de Minas.

Nossa intenção é contribuir com a estruturação acerca desse conjunto de saberes, pois os mesmos só podem ser corretamente interpretados dentro do contexto cultural em que foram produzidos. O entendimento acerca da estruturação desse conjunto de saberes, no caso em particular, o uso de plantas medicinais, pode contribuir diretamente com a implementação de políticas públicas que ajudem a integrar o saber popular ao saber científico, por exemplo. O que poderia fortalecer a perspectiva de uma saúde púbica mais integrada à comunidade e seus valores culturais.

Em relação a questão das cobranças, nossos entrevistados afirmaram que, na maioria das vezes, não há cobrança. Somente quando é demandado muito trabalho - por exemplo, exige busca de determinadas raízes no mato - é que aceitam o pagamento. Sobre essa questão, M. A. Silva afirma que "pra benzer não, não [cobro]! Só cobro o sacudimento que gasta muita coisa" (M. A. Silva, 2014). De modo geral, o sacudimento se constitui como uma cerimônia ritual que tem como finalidade limpar uma pessoa ou um ambiente de vibrações negativas. Segundo Santos (1999), esse procedimento geralmente envolve espécies vegetais, animais e certos alimentos preparados ritualmente para serem passados no corpo inteiro ou servirem de oferenda (ebós) (Santos, 1999, p. 61). Embora, nossa depoente relatasse que não cobrava para benze, destacou na mesma entrevista, que uma de suas filhas, que tinha pouco interesse em aprender acerca das benzeções, poderia precisar e, então, gastaria dinheiro com isso. Portanto, em alguma medida, o resgate acerca desses conhecimentos pode também propiciar elementos alternativos de geração de renda na região.

De modo geral, os agentes envolvidos com essas práticas são discretos e, reiteradamente procuram reafirmar que quem cura é deus. Também deixam claro que, "quando o caso é de medico", recomendam que a pessoa procure um profissional especializado. Isso fica evidente na entrevista com a senhora M. A. da Silva, de acordo com a qual: "eu falei pra ela procurar o médico, ela falou assim: Ahh, Dona Lia, to vindo de Lá! Ele mesmo 'mandou eu' vim pra cá" (M. A. Silva, 2014). O relato também traz um elemento interessante, qual seja que os médicos 
também têm indicado a procura por esses praticantes populares de cura. Não aprofundaremos essa discussão, mas ela nos mostra uma postura médica diferente daquela que acompanhamos nos jornais do início do século XX.

Não obstante a isso, as entrevistas também permitem compreender um pouco a permanência de conotações negativas acerca destas práticas de cura. Nos chamou atenção o relato da depoente Belmira, que demonstrou receio de ser associada ao "espiritismo". A entrevistada afirmava que "a benziçãozinha da gente é benziçõzinha de fé, fraquinha (inaudível) forte com Deus. Você está entendendo, não tá?” (Belmira, 2014). O esforço para de distinguir sua fé católica, de outras práticas que estariam ligadas a questões "diabólicas ou feitiçaria", compõe uma continuidade em relação ao período analisado na seção sobre a imprensa, ou seja, ainda se associa essas práticas conotações negativas e pejorativas.

Além das entrevistas de história oral, a pesquisa que deu origem a esse artigo também se construiu através de visitas domiciliares à donas de casas da cidade de Couto de Magalhães de Minas, onde foi possível fazer registros fotográficos de plantas cultivadas em seus quintais para variados fins. Ao serem indagadas acerca do porquê cultivar tais plantas, as donas de casas responderam que ao fazê-lo, evocavam lembranças da infância, assinalando momentos específicos nos quais foram utilizadas por suas mães ou avós. Na figura a seguir reunimos alguns desses registros.

FIGURA 1: Espécies vegetais de uso múltiplo citadas por moradores de Couto de Magalhães de Minas e Diamantina, MG.
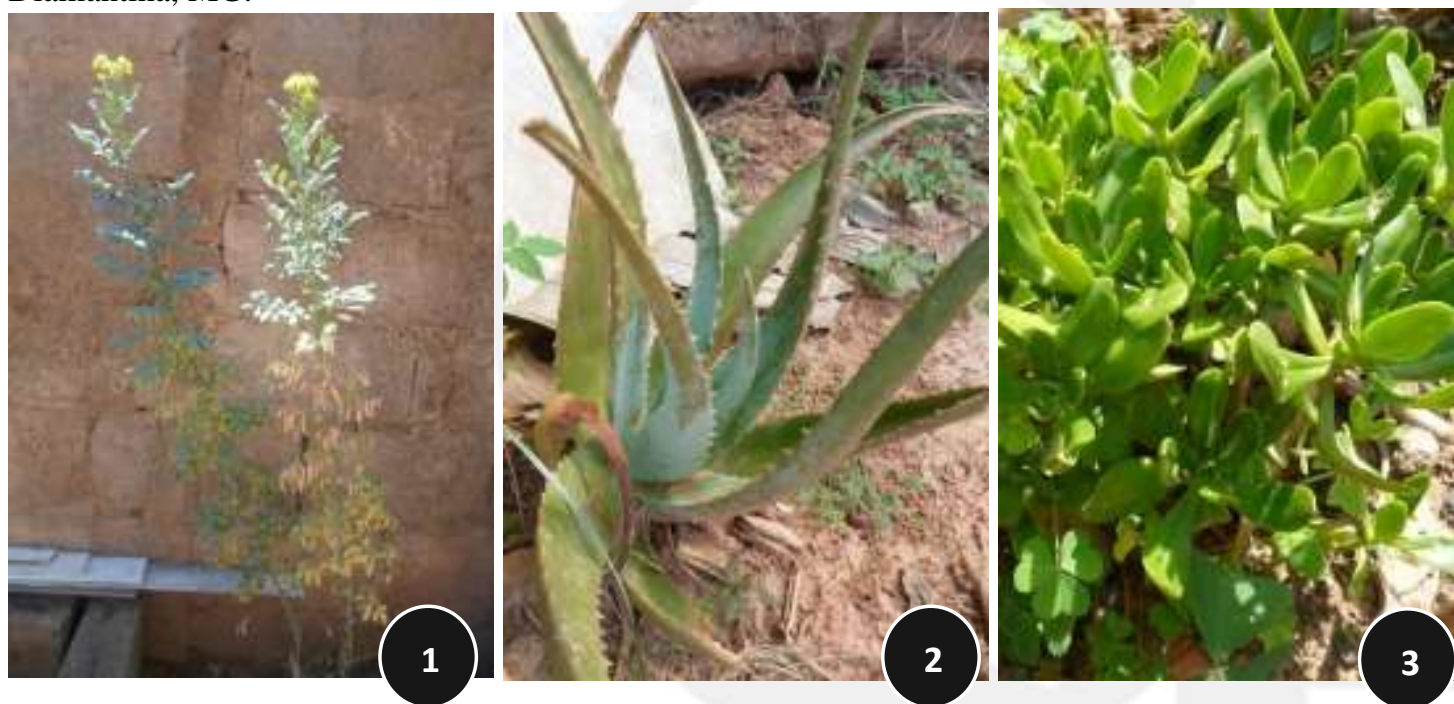


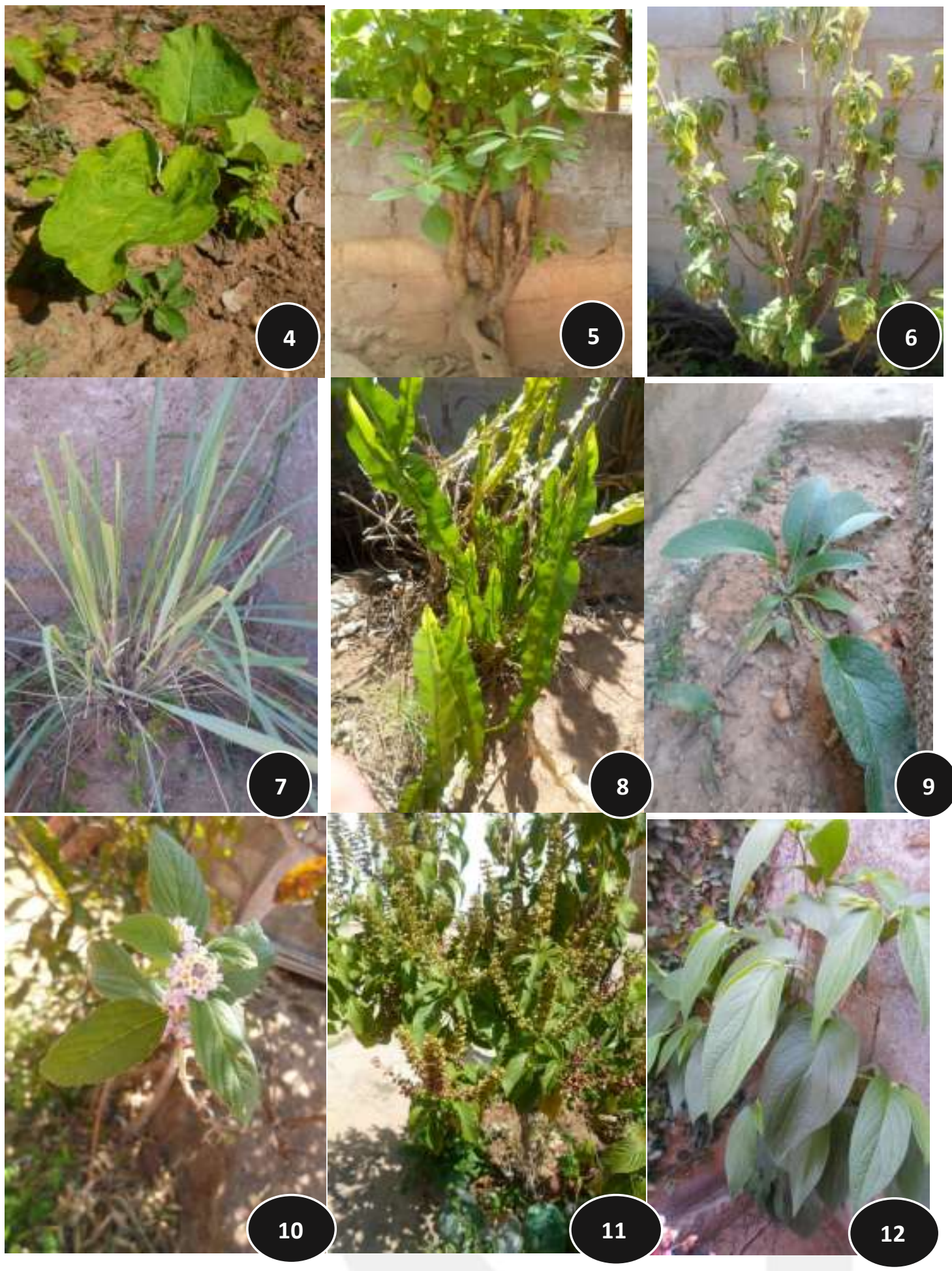




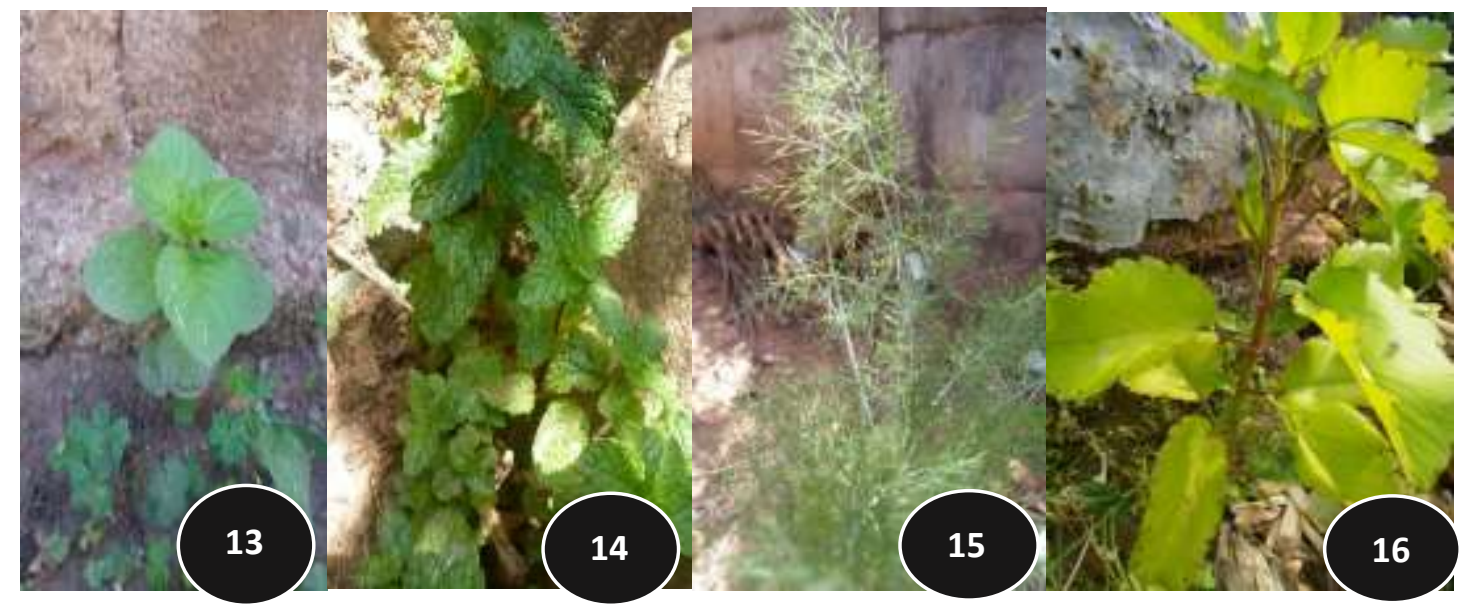

1) Arruda; 2) Babosa; 3) Bálsamo; 4) Bardana; 5) Boldo-baiano; 6) Boldo do Chile; 7) Capim-cidreira; 8) Carqueja; 9) Confrei; 10) Erva-cidreira; 11) Alfavaca; 12) Jaborandi; 13) Alevante; 14) Hortelã- roxa; 15) Funcho; 16) Saião. Fontes: Registros fotográficos realizado na casa de moradoras de Couto Magalhães de Minas.

O grande número de plantas citadas reafirma a importância de estudos que se esforcem em indicar características da etnobotânica na região. É preciso entender melhor aspectos relativos ao conhecimento tradicional, sobretudo, em relação as plantas nativas da região, com fins de contribuir para sua perpetuação. Mas, além disso, o entendimento de como esses saberes se estruturam podem ajudar na preservação das características do território da Serra do Espinhaço, que oferece os recursos para a manutenção dessas práticas, e se caracteriza pelo grande número de espécies endêmicas, muitas, ameaçadas de extinção.

Por fim, as entrevistas e registros aqui expostos indicaram que essas práticas continuam importantes para manutenção das condições básicas de saúde no Vale do Jequitinhonha, porque são parte da identidade cultural de sua população. Nas rezas, nas plantas medicinais, encontramos elementos que atuam como mecanismo de respeito ao saber local. Saber que é constituído a partir da interação com o ambiente singular da Serra do Espinhaço, somado às vivências e sociabilidades constituídas pela interação das diversas culturas que marcaram a história regional. Povos que aprenderam a perscrutar os recursos naturais, além da lógica exploratória dos diamantes, recorrendo a esses recursos de forma sustentável a fim de garantir sua saúde - no caso das plantas medicinais - e subsistência.

\section{Considerações finais}

A pesquisa sobre as práticas populares de cura no Vale do Jequitinhonha nos permitiu analisar a região a partir do viés da história da saúde, o que significa, ampliar as perspectivas de compreensão além do estigma "Vale da miséria". E, inclusive, uma análise simplista e factual poderia, até mesmo, incluir a permanência dessas práticas à lógica da miséria, ou seja, 
explicar a recorrência às curas populares à falta de recursos materiais da população dessa região. Entretanto, nossa pesquisa nos permitiu ir além e, com isso, entender que a existência, ainda hoje, dessas artes de curar expressa um processo de resistência cultural do Vale do Jequitinhonha. Pois, a perpetuação desses conhecimentos, são representativas de como o saber tradicional foi capaz de resistir às injunções históricas sofridas pela imposição do saber médico que, a partir da primeira metade do século XIX, travava uma luta por sua hegemonia no campo da saúde.

Portanto, o estudo das práticas de cura na referida região fornece evidências para a compreensão das escolhas da população diante da oferta de possibilidades para o cuidado com a saúde. Escolhas que estão relacionadas a fatores que ultrapassam a seara econômica e, se configuram, no universo de suas relações com o meio ambiente, bem como dos processos de produção e socialização de conhecimentos.

\section{Fontes}

\section{Entrevistas:}

Belmira, moradora da cidade de Couto de Magalhães de Minas. Entrevista realizada em 20/05/2014.

Francisco Otaviano Lemos, morador da cidade de Couto de Magalhães de Minas. Entrevista realizada em 16/06/2014.

Helena do Rosário Oliveira Souza, moradora da cidade de Couto de Magalhães de Minas. Entrevista realizada em 18/05/2014.

Ivete Aparecida Silva, Oliveira moradora da cidade de Couto de Magalhães de Minas. Entrevista realizada em 18/05/2014.

João José Alves, morador da cidade de Couto de Magalhães de Minas. Entrevista realizada em $16 / 06 / 2014$.

José Vicente da Silva, morador da cidade de Couto de Magalhães de Minas. Entrevista realizada em 20/05/2014.

Lea Aparecida Pereira, moradora da cidade de Couto de Magalhães de Minas. Entrevista realizada em 18/05/2014.

Mãe Lia de Oxum (Maria dos Anjos Silva Pereira), moradora da cidade de Diamantina. Entrevista realizada em 27/04/2014. 
Osvaldina Ferreira Santos, moradora da cidade de Couto de Magalhães de Minas. Entrevista realizada em 23/09/2014.

Referências bibliográficas

ALMEIDA, Diádiney Helena de. Hegemonia e contra-hegemonia nas artes de curar oitocentistas brasileiras. [Dissertação de Mestrado em História das Ciências e da Saúde]. Rio de Janeiro: Fundação Oswaldo Cruz, 2010.

CARVAlHO, Keila Auxiliadora de. A Saúde pelo Progresso: A regulamentação do trabalho médico no Governo Vargas. Rio de Janeiro: Editora Multifoco, 2015.

CARVALHO, Keila Auxiliadora; SOUZA, Ramon Feliphe de. "O Elixir da Vida": curas anunciadas nos periódicos diamantinenses do século XIX. Cadernos de Pesquisa do CDHIS, v. 29, n. 2, 2016.

CRUZ, Maria Jesus Barreto et al. Uso de plantas medicinais por famílias do Vale do Jequitinhonha, Minas Gerais, Brasil. Infarma-Ciências Farmacêuticas, v. 27, n. 1, p. 38-48, 2015.

COSTA, Thaís Ribeiro et al. Espécies de uso múltiplo utilizadas pela população em uma área do Cerrado mineiro: diversidade e valoração de conhecimento. Heringeriana, v. 14, n. 2, p. 81-106, 2020.

FERREIRA, Luiz O. Ciência médica e medicina popular nas páginas dos periódicos científicos (1830-1840). In: CHALHOUB, Sidney [org.]. Artes de Curar no Brasil: capítulos de história social. Campinas - SP: Editora da Unicamp, 2003.

FIGUEREIDO, Betânia Gonçalves. A arte de curar: cirurgiões, médicos, boticários e curandeiros no século XIX em Minas Gerais. RJ: Vício de Leitura, 2002.

GUERRERO, Patrícia. Vale do Jequitinhonha: A região e seus contrastes. Revista Discente Expressões Geográficas, no 05, ano V, p. 81 - 100. Florianópolis, 2009.

GOODWIN Jr., James William. Cidades de papel: Imprensa, Progresso e Tradição. Diamantina e Juiz de Fora, MG (1884 - 1914). [Tese de doutorado]. São Paulo: Universidade de São Paulo, 2007.

NASCIMENTO, Elaine Cordeiro. Vale do Jequitinhonha: Entre a carência social e a riqueza cultural. Revista de artes e humanidades, No 4, maio - Outubro de 2009.

NOGUEIRA, André Luís Lima. Entre cirurgiões, tambores e ervas: calunduzeiros e curadores ilegais em ação nas Minas Gerais (século XVIII). [Tese de doutorado]. Rio de Janeiro, COC/Fiocruz, 2013.

PIMENTA, Tânia S. Terapeutas populares e instituições médicas na primeira metade do século XIX. In: CHALHOUB, Sidney [org.]. Artes de Curar no Brasil: capítulos de história social. Campinas - SP: Editora da Unicamp, 2003.

REVEL, Jacques (org.). Jogos de escalas: a experiência da microanálise. Rio de Janeiro: Editora da FGV, 1998.

RIBEIRO, Palmira Margarida. Práticas de cura popular: uso de plantas medicinais e fitoterapia no Ponto de Cultura "Os Tesouros da Terra" e na Rede Fitovida na região serrana-Lumiar/Rio de Janeiro (1970-2010). [Dissertação de Mestrado]. Rio de Janeiro: COC/Fiocruz, 2014.

RIBEIRO, Ricardo. Mudando para continuar sendo: a organização de movimentos de atingidos por barragens no Vale do Jequitinhonha. In: ROTHMAN, Franklin Daniel (Org.). Vidas alagadas: conflitos socioambientais, licenciamento e barragens. Viçosa: Editora UFV, 2008. SAADI, Allaoua. A geomorfologia da Serra do Espinhaço em Minas Gerais e de suas margens. Geonomos, 1995. 
SANTOS, A. O. Saúde e Sagrado: Representações da Doença e Práticas de Atendimento dos Sacerdotes Supremos do Candomblé Jêje-Nagô do Brasil. Rev. Bras. Cresc. Desenv Hum., S. Paulo, 9(2), 1999.

SERVILHA, Mateus de Morais. Quem Precisa de Região? O espaço (dividido) em disputa. Rio de Janeiro: Consequência, 2015.

SCHWARTZMAN, Simon. Formação da Comunidade Científica no Brasil. São Paulo: Campainha Editora Nacional, 1979.

SOUZA, Laura de Mello e. O diabo na terra de Santa Cruz. São Paulo: Cia. das Letras, 1986. TORTORA, Gerard L; FUNKE, Berdell R. \& CASE, Christine L., Microbiologia, $6^{a}$ edição, Artmed Editora, 2000.

VIEIRA, Lucas Lolli. Entre Deus e os fiés: Monsenhor Horta e a cura católica em Mariana (finais do século XIX e início do século XX). [Dissertação de Mestrado]. Rio de Janeiro: COC/Fiocruz, 2015.

VISCARDI, Claúdia M. R. Federalismo e cidadania na imprensa republicana (1870-1889). Tempo vol.18 nº 32 Niterói, 2012. 